\title{
SEMIOLOGIA E PINTURA SEGUNDO RENÉ PASSERON
}

\author{
Wilcon PEREIRA*
}

\begin{abstract}
RESUMO: Trata-se de uma síntese das principais idéias de René Passeron a propósito da fundamentação de uma análise lingüístico-semiótica das obras pictóricas. Em que medida um quadro pode ser considerado um texto? Quais seriam os elementos básicos de uma pintura? Podemos falar em articulaçðes de unidades no campo visual definido por uma obra dessa natureza? E quais os repertórios e as regras combinatórias? $O$ artigo propðe a discussão destes problemas a partir das rigorosas e oportunas colocaçoes do importante teórico, crítico e historiador da arte, infelizmente quase desconhecido entre nós.
\end{abstract}

UNITERMOS: Semiologia, estética, ciências humanas, filosofia da arte, pintura, cor, linhas, valores, significação, linguagem, código.

\section{Estética e Ciências Humanas}

Recentemente um ensaista italiano, Armando Plebe, reuniu em livro polêmico algumas das principais críticas e objeções movidas contra a estética (11). Conseguiu elaborar assim, como se pode prever, um alentado dossiê de acusação. Amostras dessas idéias, que foram sobrevivendo geraçōes após gerações: a impossível universalização dos juízos de gosto, o mercado caráter ideológico das análises, a irrealizável obtenção de uma terminologia precisa, e assim por diante. Em última instância, enfim, as acusações reduzem-se a poucos denominadores comuns já muito popularizados, difusos e insidiosos. Por isso mesmo, aliás, constituindo núcleos de resistência tão cristalizados, que se corre o risco de jamais dissolvê-los integralmente.

Escusado será dizer que não se trata, portanto, de ninharias ou restrições de somenos. Inversamente, tudo isso vale como sintoma de uma crise muito profunda. Pois uma série enorme de questões, em volta das quais uma tradição milenar se organizara, vem sendo posta em xeque ul- timamente e começa até a ser dispensada, a título de elenco de falsos problemas ou de problemas mal colocados.

Mais ainda, conforme nota Bernard Teyssèdre (referindo-se a temas como o do belo em si, a distinção entre o bom e o mau gosto, as tentativas de classificar e mesmo de hierarquizar as diversas formas de arte), praticamente nada escapou "que mereça ser colocado como problema" (14). Isto posto, essa disciplina filosófica estaria ameaçada, por via de conseqüência, de completa marginalização, de ver-se excluída "do que poderia ser uma autêntica reflexão sobre a arte" (15).

Mas, afinal, como se articularia um discurso sobre arte que fosse na verdade uma "autêntica reflexão?" Quais seriam então os seus fundamentos?

Desejamos lembrar aqui, e com as devidas cautelas, uma fórmula que tem sido experimentada com grande empenho. Pensamos nas aproximações, cada vez mais freqüentes, entre a filosofia da arte e as ciências humanas. Com efeito, tem-se buscado progressivamente na história ou

Professor Assistente-Doutor do Departamento de Filosofia - Faculdade de Educação, Filosofia, Ciências Sociais e da Documentação - UNESP - 17500 - Marilia - SP - Brasil. 
na sociologia, na psicologia ou na etnologia, os tão necessários pontos de apoio a fim de estruturar-se uma teoria da arte menos vaga e hesitante do que as precedentes, quase sempre muito genéricas e abstratas. Essas convergências são hoje encontradiças em pesquisas (por sinal muito divergentes) como as de Francastel ou de Panofsky, de Gombrich ou de Read, para só falarmos nestas.

Com maior ou menor dose de ingenuidade ou de suspicácia, avizinham-se portanto das ciências humanas - também em fase de constituição, observe-se - todos aqueles teóricos e críticos que, de um modo ou de outro, preocupam-se com o rigor metodológico das investigações, com a formulação de terminologia coerentes, de interpretações bem circunscritas e referenciadas. O ef eito geral revelase inclusive bastante promissor. Se as vastas hipóteses explicativas vão se tornando mais raras, o discurso no seu todo se beneficia com um certo jejum especulativo, dobra-se sobre si mesmo com maior assiduidade e cuida de basear-se necessariamente em dados concretos $(14,15)$.

Toda esta conivência entre filosofia e ciências humanas está longe de ser um traço marcante apenas de reflexão sobre arte. Bem ao contrário, estamos diante de um movimento global, que abarca todas as disciplinas filosóficas em suas mais contemporâneas reformulações, da teoria política à filosofia das religiões. Logo, o que se propõe aqui para a estética é somente um pequeno fragmento no âmbito de um bloco ainda mais extenso e significativo. Do qual pouco se cuidará aqui, por circunstânciais razões de limites espaciais. Mas que deve ficar subentendido, como pano-de-fundo essencial.

\section{Estética e Semiologia}

A rede produzida pelas interconexões entre filosofia e ciências humanas trouxe para a ordem do dia, com ênfase toda especial, o problema das significações. Vislumbra-se no enfoque comum desta questão uma real possibilidade de unificar todas as pesquisas em curso. Mas, para tanto, foi indispensável reduzir, como ponto de partida, a totalidade dos fenômenos culturais a processos de comunicação. Vale dizer: considerá-los sistemas de signos perfeitamente ajustados às necessidades das transmissões e recepções de mensagens.

Contudo, ao mesmo tempo que a vida social era abordada como tessitura complexa de dinamismos comunicacionais, a própria noção de significação foi levada necessariamente a sofrer ampliações. Houve então uma “extensão praticamente ilimitada da significação", na expressão de Dufrenne ${ }^{(2)}$. O conceito passou a incluir uma gama bastante variada de fatos. A linguagem natural, os sinais trocados por seres das espécies subumanas, os rituais, os sistemas de parentesco, todos esses conjuntos simbólicos passaram igualmente a ser considerados como geradores de significações. Desta forma, a ciência geral dos signos, postulada por grandes pioneiros como Saussure ou Peirce, assumiu uma inquestionável posição de ciência-piloto. Como não poderia deixar de ocorrer, os reflexos destas novas perspectivas sobre a estética foram imediatos. O que é, aliás, bastante justificado, uma vez que se julgou evidente a afinidade entre obra de arte e sistema de significação. Mais evidente, pelo menos à primeira vista, do que entre tais sistemas e os laços de parentesco ou as comunicações praticadas entre animais. Está claro que essa certeza preliminar logo se revelaria parcialmente falaciosa e o muito menos transparente do que se imaginara, conforme também verificaremos adiante.

De qualquer modo, importa-nos destacar nesta passagem o surgimento e a rápida afirmação de alguns programas para uma estética de fundamentos semiológi- 
cos. Neste domínio, então, inéditos horizontes se abrem, a reflexão sobre arte sentindo especialmente o que Barthes chamou de "solicitação semiológica" (1). E isso, na prática, desde os primeiros momentos, enraizando-se já nos primórdios desta ciência que se deveria encarregar de estudar "a vida dos signos no seio da vida social"' (12).

Pois, com efeito, nos próprios cursos de Saussure, na década de 10 , já se tenta vincular arte e semiologia, ainda que de forma quase acidental e fragmentária, quando o mestre de Genebra lança mão do exemplo das várias ordens de coluna (jônias, coríntias) como materiais apropriadíssimos a fim de ilustrar o que teorizava sobre paradigmas e sintagmas (13). Por sua vez, desde o final da década de 30 o norte-americano Charles Morris, derivando suas hipóteses do pensamento de Peirce, tratava o processo artístico como um fenômeno sígnico, os produtos estéticos sendo por ele considerados modalidades da "iconic signs" (5). E também Roman Jakobson, de sua parte, não hesitou em extrapolar os modelos lingüísticos para os demais sistemas semióticos, inclusive os que cumprem sobretudo funções estéticas; leve-se em conta, nessa ordem de idéias, o seu exemplar estudo a propósito dos conceitos de metáfora e metonímia, aplicados também ao cinema e à pintura (3)

Detenhamo-nos nestes casos-limite que, a nosso ver, mostram suficientemente os liames originários entre a semiologia nascente e a investigação a respeito das obras de arte.

\section{Semiologia da Pintura}

Nessa linha de interesses, particularmente decisivas são as sondagens visando construir uma semiologia da pintura. Herdeira de uma tradição muito sólida, era inevitável que a teoria das artes plásticas se integrasse também nestas pesquisas interdisciplinares. Não lhe faltavam mesmo fontes motivadoras no próprio contexto de nossa época. Tenha-se em conta, por exemplo, as instigações representadas pelo sucesso obtido graças à aplicação de esquemas semióticos ao exame das obras literárias, desde os formalistas russos até Todorov ou Greimas, passando evidentemente pela análise de Les Chats (de Baudelaire) por Jakobson e Lévi-Strauss em parceria.

Porém, de forma geral, foi uma certa atmosfera cultural, no seu todo, que incentivou de modo especial esse tipo de abordagem; um clima de euforia, motivado em larga medida pela confiança nas possibilidades do método estrutural, plenamente identificado com as análises dos sistemas simbólicos, das quais a lingüística representava, segundo Verón, uma "privilegiada vanguarda", (16). Um dos pioneiros nessas aplicações ao universo de pintura de instrumentos originariamente lingüísticos e semiológicos, Abraham Zems, conf essa-o explicitamente: movia-o o fato de sentir-se fascinado pelos "métodos precisos e fecundos", pelas “categorias lingüísticas e estruturais", que se haviam mostrado tão operacionais nos estudos sobre mitologia, música, parentesco (17).

Fruto da mesma inspiração foi ainda o ensaio de Louis Marin, Elementos para uma semiologia pictural, tentativa de organizar um corpo sistemático de princípios, conceitos e modelos explicativos, na qual se assumia integralmente os pressupostos da translingüística proposta por Roland Barthes. Assim, no referido trabalho, igualmente se dá por estabelecido que as imagens e figuralidades podem significar, mas nunca de maneira autônoma, pois a. substância visual necessita sempre da linguagem que recorta os significantes e constitui os significados. "A linguagem intervém constantemente", afirma Louis Marin, trilhando os caminhos abertos por Barthes, "para duplicar o que é visto pelo que é dito, onde a ima- 
gem, o visível é sem cessar refratado na e pelas categorias da linguagem",(12).

\section{A Pintura é Linguagem?}

No entanto, esse modo de encaminhar as pesquisas de incipiente semiologia do objeto pictural não deixou de provocar muitas controvérsias. Efetivamente, contra ele insurgiram-se muitos teóricos e críticos ligados às principais orientações filosóficas contemporâneas. Uma frente única delineia-se assim, englobando neopositivistas e fenomenólogos, marxistas e pensadores que se apóiam em descobertas freudianas. Lembramo-nos aqui, de passagem e sem qualquer pretensão quanto a esgotar a enumeração, figuras tão representativas como Suzanne Langer, Dufrenne, Lyotard, Galvano della Volpe, Goodman (18).

No fundo, o centro de polêmica pareceu-nos estar localizado no fato de que os semiólogos da arte procedem como se fosse tranqüila, obviamente positiva, a resposta à pergunta-chave e preliminar: a pintura é linguagem? Quando bem vistas as coisas, não há por enquanto (e talvez não se consiga jamais) o menor vislumbre de consenso a respeito. Somente por um vício de base é que se parte, a priori, de uma tão pacificadora solução: o logocentrismo. Inclusive porque na própria formulação pelo menos duas subquestões se imbricam, ambas igualmente à espera de um esclarecimento prévio. Se não, vejamos.

Primeiramente, está em causa a pintura propriamente dita, sua especificidade e funções particulares; até que ponto se poderia então identificá-la com a linguagem ou transportar modelos lingüísticos para o seu enfoque? Em segundo lugar, sabe-se que o termo "linguagem" é fortemente polissêmico, como tal utilizável nas mais diversas acepções e níveis, de acordo com as necessidades do momento: logo, não se estaria em perigo de cometer sofis- mas e jogos verbais, fazendo render as ambigüidades do conceito?

\section{Erudição e Vivência}

Todo esse complexo de dificuldades, para o qual mais se apontou do que propriamente se discutiu, deve servir como ponto de referência constante para um desígnio mais limitado: o desejo de apresentar alguns dos traços mais salientes da reflexão de René Passeron sobre o emaranhado de problemas que envolvem a semiologia da pintura.

Anima-nos nesta empresa, antes de mais nada, uma observação de Mounin: 'Em vez de colocar a priori que a pintura é ou não é uma linguagem, e depois tratar de demonstrá-lo, Passeron procura o que é, especificamente, a pintura",(6).

Inicialmente, porém, certas informações indispensáveis a respeito do autor que, estranhamente ainda não "entrou em moda", tanto no Brasil quanto na França. Trata-se, na verdade, de um curioso misto de "scholar" e de artista criador, pois abandonou a pintura depois de muitas exposições individuais e coletivas para dedicar-se às investigações filosóficas e psicológicas, como membro do Centro Nacional de Pesquisa Científica, em Paris. Tem assim a rara vantagem de juntar as duas pontas da meada: vivência direta da produção e trabalho teórico sobre arte. Por isso mesmo, talvez, suas publicações revelem um espírito menos dogmático, voltado mais para as argumentações e exemplificações do que para as soluções apressadas.

Sua obra referente à matéria sob análise não é ainda muito extensa. Limita-se a um levantamento histórico do movimento surrealista (7); uma introdução, bastante simples e didática, ao universo da pintura considerado na sua totalidade (8); um estudo monográfico das pinturas de Magritte $\mathrm{e}^{(9)}$; e, primacialmente, um exaustivo tra- 
tado sobre a obra pictural e as funções da aparência (10). Importam-nos sobremaneira aqui, por concernirem imediatamente às questoes que nos preocupam, duas passagens fundamentais: o capítulo VII de Clefs pour la peinture, intitulado " $\mathrm{P}$ intura como Linguagem"' (p. 116 a 135), que citaremos como C.P.; e o item número 4 da terceira parte de L'Oeuvre Picturale et les fonctions de l'apparence, intitulado "A Pintura como Linguagem" (p. 207 a 234), que citaremos em seguida como O.P. $(8,10)$.

Muito condensadamente, nessas poucas páginas, o ensaísta percorre todo o espaço de reflexão constituído pela semiologia da pintura. Nem sempre o faz, está claro, com intenções exaustivas, mesmo porque seriam quase nulas as suas possibilidades de esgotar as interrogações propostas, por limitaçð̃es de páginas. Contudo, mesmo que seja em grau mínimo, recoloca e reordena toda a problemática, que está delimitada, nestas suas claríssimas exposições, que por uma contraposição de determinadas linhas-mestras igualmente freqüentes na bibliografia sobre pintura:

a) A idéia de que o elemento definitório da pintura é a mímesis, o analogon servindo de critério para se distinguir e valorizar a obra bem realizada.

b) A obra pictórica vista como realidade em si, espécie de prolongamento da natureza, correalidade que existe de per si e como tal podendo gerar um cosmos autônomo.

c) A pintura como veículo de informação, instrumento para a comunicação social, meio útil para a transmissão de conteúdos políticos, religiosos, didáticos, amorosos, etc.

d) A hipótese que o autor assume bem explicitamente, segundo a qual a obra pictórica é essencialmente uma forma de expressão, sendo este o seu traço de maior pertinência, sua garantia de especificidade. A mímesis só teria alcance quan- do também exprime; a obra é realidade em si pelo mesmo motivo; sem ela o trabalho vira imagerie, cromo, kitsch sem qualquer importância ou sabor original; assim, a comunicação pode ser um acréscimo e jamais o ponto central, função desempenhada unicamente pela expressão.

\section{A especificidade da Pintura}

Comecemos por um maior aprofundamento da noção de especificidade da pintura, na qual Passeron tanto insiste: haveria, como nos propõe, uma essência do pictural, que não se pode rejeitar sem sair ato contínuo desse domínio particular. Como seria, então, essa pintura en sich?

Em primeira instância, um subjectile, superfície virgem, mais comumente plana, constitutiva de um campo visual delimitado. Nela o pintor vai escrever os signos através de quatro elementos fundamentais: o desenho, que marca os contornos sobre a ref erida superfície; os valores, ou diversos graus de claro-escuro; as cores, suas pigmentaçðes, dimensões e múltiplas tonalidades; enfim, os empastamentos, sejam os transparentes e límpidos das pinceladas a prima, ou as camadas superpostas, ou mesmo os ef eitos de relevo usados por certos materistas (como Dubuffet, por exemplo).

Estes quatro "elementos plásticos", (C.P.p.126) entram em combinações infinitamente originais e diversificadas. Definem-se assim as formas expressivas propriamente picturais: "A composição destes elementos em um todo que se apresenta como unitário e harmonioso, mesmo que seja mediante uma seleção entre tais elementos, desembocando na elaboração de um estilo"'. (O.P. p.208). À luz desta definição já não tem qualquer pertinência uma discussão a respeito da eventual superioridade do abstracionismo ou do figurativismo, do geometrismo ou do informalismo, para nos restringirmos só a 
alguns rótulos tão usuais. Ao contrário, podem ser formas expressivas, de igual sorte e com idêntico mérito, tanto as manchas da pintura gestual quanto a plástica pura dos construtivistas, tanto a pinturaescrita de Klee quanto as monocromias de Klein.

Todavia, o autor dá em seguida um passo adiante. Retomando os termos de Étiènne Souriau, um dos grandes mestres da estética francesa, caracteriza as formas expressivas de modo ainda mais preciso: são "formas compendiosas", "figuras abreviadas"' (O.P., p.214). Ou seja, figuralidades mais ou menos simplificadas, portanto mais ou menos abstratas em todos os casos, "onde o expectador deve reencontrar alusivamente uma realidade conhecida dele"'. (O.P., idem). O compedium, entendido deste modo, sintetiza no campo visual "uma série de movimentos, de trajetórias, de caminhos operados ou percorridos por nós, por nós observados; logo, vividos numa experiência quotidiana e numa situação"' (O.P. p.215). Todos esses fatores, naturalmente, enraizando-se num determinado meio sócio-geográfico, numa etapa da história, numa vertente de certa civilização, o que faz deles inclusive "grandes temas estruturais de nossa inserção fisiológica e psicológica no mundo"' (O.P.p.219).

Repousando e m tais princípios, uma nova conclusão vai necessariamente se impor. A pintura é concebida por Passeron como uma das funções simbólicas, teorizadas por Ernest Cassirer (O.P.p.210-11). Especificamente, esse meio de expressão transforma uma região particular do universo, o "domínio das aparências visuais"; pois a função da aparência (O.P. p.210). Compondo no subjectile, o pintor transpõe e modifica as aparências ou impressoẽs visuais, ao passo que o cientista intervém diretamente sobre as próprias coisas, revelando assim uma outra forma simbólica de caráter essencial.

\section{Pintura e Escrita}

Consideremos a mesma questão da especificidade da pintura sob outro ângulo. No caso, como faz repetidas vezes o autor que comentamos, lembrando de saída que a pintura é tão-somente um sistema de expressão entre muitos outros, postos em ação na exata medida em que: "As línguas que o homem fala não bastam, quaisquer que sejam as riquezas de seu vocabulário e a leveza de sua sintaxe, para satisfazer seu desejo de exprimir-se", (C.P.p.116).

Assim, mesmo para nos confinarmos aos sistemas gráficos de expressão, dezenas seriam os exemplos daqueles que também agenciam em suportes planos e delimitados os elementos básicos já destacados. Não obstante, a pintura representa um processo bastante particularizado e irredutível às demais formas de exprimir por meio de linhas, cores, empastamentos e valores. Para demonstrá-lo convenientemente, aliás, Passeron não economiza esforços, aproximando-o e diferenciando-o de sistemas tão dif undidos (e sempre muito úteis, do ponto de vista estritamente pragmático) como os pictogramas, mapas, sinalética de trânsito, tabelas estatísticas e gráficos de todas as naturezas.

Lastimavelmente, seria descabido refazer aqui estas brilhantes análises. Em compensação, concentramo-nos um pouco mais pormenorizadamente nas linhas gerais de seu pensamento quando relaciona pintura e escrita. Trata-se de uma questão oportuníssima, o autor precisando necessariamente enfrentar um dos estereótipos mais resistentes da crítica e da filosofia da arte: referir-se à pintura - ou ao desenho, ou à gravura - como escrita, ou como écriture, segundo o tão empregado galicismo.

O encaminhamento dado por Passeron é no sentido de desidentificar esses dois sistemas de modo radical. A escrita é concebida por ele como pura e simples fixação da linguagem articulada (oral). 
Além de funcionar então como mediadora, a escrita apóia-se em códigos de uso coletivo, instituídos por convenção, o que assegura a univocidade dos léxicos e a objetividade das regras sintáticas. As linhas, os valores e as cores nela eventualmente empregados são, por princípio, elementos postos a serviço de uma transmissão de informações no nível institucional, de uma comunicação social.

Em contrapartida, a pintura é expressão em sentido forte: expressão de um indivíduo e em obra irrepetível. Por meio das "qualidades da escrita", subentendese pois uma estilização singular, uma interpretação pessoal do tema visto ou imaginado: "A escrita pictural é, portanto, construída diretamente (o que não quer dizer simplesmente) a partir do objeto a significar, ou do domínio do real a ser dominado"' (O.P. p. 228). Conseqüentemente, distingue-se da escrita com caracteres que, hieroglífica ou alfabética, correspondendo a uma língua falada e da qual se deseja fixar o discurso, busca ser, ao contrário, em sua caligrafia, o mais convencional possível"' (C.P. p. 118).

Por acréscimo as unidades da escrita podem tornar-se também expressivas, ao menos em grau razoável. Indiquemos um exemplo bastante curioso, a fim de complementar o exame que viemos de resenhar. Em muitas obras contemporâneas surge maciçamente uma figuração da escrita, letras ou frases em Klee, Magritte, Schwitters, Indiana, Isou, Mira Schendel, Rubens Gerchman e tantos outros. O material escrito ganha assim, nestes trabalhos, inesperadas qualidades plásticas: dimensões, relevos, ritmos, cores. Ou seja, afastam-se parcialmente da grafia convencional, rompem com os esquemas habituais de representação da linguagem oral. Porém, tal força expressiva é uma violentação à natureza essencial da escrita que "busca ser o mais convencional possível"'. De fato, nestas produções atuais o elemento escrito já se deixa inte- grar no universo pictórico como "domínio do real a ser dominado", a ser metamorfoseado em outras formas expressivas compendiosas.

\section{A Teoria da Linguagem Expressiva}

É tempo, agora, depois de todas estas curvas e rodeios, de voltar à pergunta motivadora: a pintura é uma linguagem? Acompanhando os raciocínios de Passeron, como o fizemos, tudo levava a crer que forçosamente se recusaria uma identificação entre ambas. Após trazer à luz o caráter específico de art d'expression da pintura (conforme diz, algo retoricamente, em C.P. p.120), sem dúvida o coerente seria aprof undar esse veio, sondá-lo até às últimas conseqüências. Aliás, toda a separação entre pintura e linguagem, como duas ordens inassimiláveis de operações semióticas, já estava suficientemente preparada nos trechos referentes à distinção entre pintura e escrita. Mas outras declarações teóricas de caráter geral, muitas vezes repetidas, são também inequívocas, afastando a investigação da "teoria lingüística das artes plásticas"'. Veja-se esta afirmação: "Guardemo-nos de aplicar mecanicamente nos fenômenos estéticos os quadros elaborados para a linguagem articulada, para as línguas, e de fazê-los convir à força". (C.P. p.121). Ou esta passagem, na qual se afirma que a verdadeira tarefa não seria demonstrar "o modo como ela (a pintura) poderia entrar num sistema constituído por e pela linguagem articulada...mas sobretudo qual é o modo de proceder do sistema que lhe é próprio"' (O.P. p. 226-227).

Todavia, esta é apenas uma face da moeda, que isolamos a fim de suprir as provisórias necessidades da exposição. A realidade é mais complexa, um outro propósito vindo juntar-se ao primeiro e gerando inclusive muitas contradiçūes internas. Com ef eito, não poderíamos deixar passar sem nenhum reparo o fato de que Passeron se mostra igualmente fascinado 
pelos prestígios da lingüística, o que vem comprometer quase irremediavelmente o seu discurso. Numa decisão metodológica altamente discutível e sem qualquer embasamento principial mais sério, o autor força uma aproximação entre os dois sistemas, faz com que a pintura seja tomada de maneira incaracterística como híbrida “linguagem expressiva"' (O.P. p.226).

Leia-se, para ilustração, este parágrafo: "Em suma, para considerar a pintura sob o ângulo da linguagem, devemos substituir ao par significado-significante, estudado por Saussure, o par expressadoexpressante"' (C.P. p. 133). Basta, salvo erro de nossa parte, para que se fique consciente do seu afã de traduzir em outro registro os dados que pusera em relevo ao analisar a especificidade das formas expressivas da pintura enquanto tal, inconfundíveis por princípio e por natureza.

O uso desses conceitos de inspiração saussureana, a inesperada assunção da ótica lingüística, tudo isso acaba por se mostrar teoricamente inócuo e sem o menor futuro, levando-nos somente a um jogo verbal inconseqüente. Mas, por outro lado, patenteia-se o claro desejo de integrar-se às orientações mais em evidência, importando e decalcando termos que já se demonstraram fecundos em outros domínios científicos. Pois, afinal de contas, por que domesticar o sui generis da pintura, obrigando-a a entrar no universo dos signos lingüísticos? Importa realmente uma consideração das formas expressivas pictóricas "sob o ângulo da linguagem"? O mais enriquecedor não seria exatamente a dissociação entre ambas? Não é então por serem distintas que cumprem funções igualmente básicas, insubstituíveis e irredutíveis?

Ademais, julgamos também inócuas as traduções de conceitos empregados para denominar recursos técnicos em palavras tomadas de empréstimo à lingüística. Isso não lhes aumenta a clareza e não garante que sejam efetivamente os únicos elementos fundantes da arte pictórica. Assim, não enriquecemos a semiologia da arte quando chamamos as linhas, as cores, os empastamentos e os valores de "elementos semânticos"' (C.P. p. 126); nem se lhes atribuirmos as propriedades de "vocabulário essencial"'; menos ainda se damos curso a primárias assimilações entre a combinatória dos quatro elementos e os códigos lingüísticos, as paroles, as gírias, as langues, as gramáticas, etc. (C.P. p.126 e 133).

O perigo que nos espreita, no caso de endossarmos e levarmos adiante essas soluções de simplicidade, é bastante conhecido; contentarmo-nos com a mera superposição de termos e modelos, que se revelaram operacionais no conhecimento de uma certa região, quando do tratamento de um outro setor talvez absolutamente diverso. Eis aqui uma estrada real, que desemboca novamente no dossiê de acusação ao qual nos referimos de início, agora reforçando o capítulo (por enquanto) derradeiro, intitulado Estética Semiológica.

\section{Linguagem e Sistemas Significantes}

Dissemos, há pouco: duas faces de uma mesma moeda. Mas não se trata de posições tão discerníveis e isoláveis. Ao contrário, os fios se enredam, num só parágrafo às vezes se entretecendo a plena consciência da especificidade da pintura e a tentativa de reduzi-la às categorias da lingüística. O que, sem dúvida, é ainda mais grave, pois torna quase impraticável a localização dos verdadeiros motivos responsáveis pelos equívocos do autor.

A despeito disso, vislumbramos pelo menos uma razão que nos parece decisiva e queremos expô-la nestas linhas finais. Ao que tudo indica, Passeron confunde de modo um tanto ingênuo os sistemas significantes (em geral) e um sistema significante muito particular: a linguagem. No entanto, desde Ferdinand de Saussure, ela vem sendo considerada apenas um desses sistemas, embora a tal ponto fun- 
damental e privilegiado que o tomou como padrão para o estudo dos demais. Assim, na própria linhagem saussureana, onde pretende encaixar-se, poderia descobrir os meios necessários e suficientes para compreender a estrutura da linguagem - dupla articulação, arbitrariedade e linearidade dos signos, códigos socializados, etc. - como espécie de um gênero mais amplo: a prática semiótica generalizada.

$O$ autor peca na base, contudo, por desconhecer na prática essa hierarquia, ou por não levá-la suficientemente em conta, voluntária ou involuntariamente. Há um exemplo bastante nítido, quando explica a passagem das formas expressivas para signos utilizáveis na comunicação social. Em torno da forma originária (individual, isolada, solitária) os usuários da pintura (galerias, museus, críticos, amadores, simples curiosos) iriam cristalizando aos poucos os valores estéticos, emocionais, intelectuais, políticos, morais, religiosos. Essa "semantização a posteriori" prolongar-se-á talvez ad infinitum, ampliando e enriquecendo os significantes que funcionam tão como fábricas incessantes de novos significados: "A significação vem ao signo posteriormente, por um fenômeno sociológico e histórico de penetração no público, que transforma em comunicação semântica as formas inventadas de início para serem apenas elas mesmas"' (C.P. p. 129-130).

Só nos resta concordar com tão oportuna esquematização dessa gênese da significação, que nos permite descobrir como escorrimentos viram quadros de Pollock ou como retângulos passam a ser admirados como obras de Mondian. Não se percebe, todavia, nenhuma justificativa para se designar tais resultados como "linguaguem", mesmo que seja um tipo anômalo da "linguagem expressiva", pois é de sistema de significação não-ligüística que se deveria falar, bem precisa e circunstanciadamente.

Passeron deixa fugir, deste modo, uma excelente oportunidade para explo- rar até ao fim sua primeira intuição: uma semiologia da pintura deve estabelecer, logo de início e com firmeza, a autonomia desta como estrutura de significação; a problemática organizar-se-á a partir de uma localização das suas unidades mínimas, das suas regras de articulação, das funções que o sistema desempenha nos processos de comunicação, na margem de expressão individual que pode eventualmente assegurar aos praticantes e usufruidores. Em vez disso, o ensaísta prefere manter alguns clichês tão cômodos quanto inexpressivos. Pensando em termos de "linguagem", metafórica e diluidamente, poẽ de lado os problemas centrais de uma "autêntica reflexão sobre arte" que se apóie na semiologia: que é um sistema de significação? Como os elementos plásticos podem lançar significados de alcance social? Por que a linguagem natural não satisfaz na integra as necessidades humanas de comunicação? Qual a fronteira entre a expressão e a mera informação?

Georges Mounin, sempre tão elogioso quando se refere à pesquisa de Passeron, chega a afirmar: "A única tentativa de analisar um sistema (talvez) de comunicação não-lingüística sem recorrer a priori ao esquema lingüístico foi $A$ obra pictural $e$ as funções da aparência de René Passeron - livro que seria mais conhecido se trouxesse seu verdadeiro título: é ao menos o esboço acentuado de uma Semiologia da pintura (6). Para rematar, queremos contradizê-lo frontalmente. Em primeiro lugar, se não recorre a priori ao esquema da lingüística é porque desenvolve um expediente ainda mais absurdo: limita-se à sobreposição do instrumental desta disciplina a uma região diferenciada. Por outra parte, assim procedendo, não chega sequer a esboçar um programa mínimo de investigação, um plano-piloto que abrisse novas perspectivas para a semiologia da arte.

No entanto, por sob as contradições de seu discurso, em certos momentos de 
maior felicidade Passeron marca fortemente a heteronomia da obra de arte e obtém inclusive uma formulação definitiva do problema mais inquietante. Leiamos, a título de confirmação, mais esta passagem, de tal lucidez que já bastaria para justificar nossa intenção de divulgar seu pensamento: "conta-se que Picasso respondeu a uma dama que se lamentava diante dele por não compreender sua pintura: "Madame, a senhora conhece chinês? - Não? Pois bem, aprenda-o!'”. Há prof undidade nesta lição. A sensibilidade se educa. Ela se ilumina. Diremos que a pintura (para o expectador) se aprende como uma língua? A dama poderia ter pedi- do a Picasso que lhe indicasse uma gramática, quem sabe até um método assimil. $\mathrm{O}$ pintor tê-la-ia remetido aos historiadores da arte e aos museus. Ela teria compreendido Picasso ao estudar Rembrandt. Eles falam, então, a mesma língua?' (O.P. p. 224).

Esta providencial meditação, que adaptamos para o português, deveria servir como uma espécie de Koan para os aprendizes da filosofia da arte, de semiologia da pintura, de estética semiológica. E mais ainda, talvez, para os aprendizes de pintura - motivação primordial de nossos esforços.

PEREIRA, W. - Semiology and paiting according to René Passeron. Trans/Form/Ação, São Paulo, 4:61-71, 1981 .

ABSTRACT: The present article is concerned with René Passeron's thoughts about the fundamentals of a linguistic-semiotic analysis of pictorial works. To what extent can a painting be considered a text? Which would be the basic elements in a painting? Can we speak about articulations of unities in the visual field defined by an art work of this nature? And which would be its repertories and combination rules? This paper proposes a discussion of problems such as these departing from the rigorous and opportune considerations made by the important theoretician, critic and art historian unfortunately almost unknown among us.

KEY-WORDS: Semiology; aesthetics; human sciences; philosophy of art; painting; color; lines; values; meaning; language; code.

Recebido em 26/2/1981.

\section{REFERÊNCIAS BIBLIOGRÁFICAS}

1. BARTHES, Roland - Présentations. Comunications (4):1, 1964.

2. DUFRENNE, Mikel - Esthétique et philosophie. Paris, Klincksieck, 1967, p. 75 .

3. JAKOBSON, Roman - Dois aspectos da linguagem $\mathrm{e}^{\prime}$ dois tipos de afasia. In: Lingüística e comunicação. Trad. José Paulo Paes e Isidoro Blikstein. São Paulo, Cultrix, 1969. p. 34-62.

4. MARIN, Louis - Élements pour une sémiologie picturale. In: TEYSSËDRE, Bernard et alii. - Les sciences humaines et l'oeuvre d'art. Bruxellas, La Conaissance, 1969, p. 111.

5. MORRIS, Charles - Signes, language and behavior. New York, Prentice Hall, 1946.
6. MOUNIN, Georges - Peinture et language. In: Introduction à la semiologie. Paris, Minuit, 1970. p. 272276.

7. PASSERON, René - Histoire de la peinture surréaliste. Paris, Le Livre de Poche, 1968.

8. Clefs pour la peinture. Paris, Seghers, 1969. - Odège. 1970.

10. L'oeuvre picturale et les fonctions de l'apparence. 2. ed. Paris, J. Vrin, 1974.

11. PlEBE, Armando - Processo all'estetica. Firenze, La Nuova Italia, 1969. 
12. SAUSSURE, Ferdinand de - Cours de Linguistique génerale. Ed. crítica por Tullio de Mauro. Paris, Payot, 1972. p. 33.

13. Idem - p. 171

14. TEYSSĖDRE, Bernard - La refléxion sur l'art. In: TEYSSËDRE, Bernard et alii. Les sciences humaines et l'oeuvre d'art. Bruxellas, La Connaissance 1969. p.8.

15. Idem p. 9.

Um excelente resumo do estado atual da questão na publicação coletiva supracitada, juntando artigos sobre arte e sociologia, etnologia, psicanálise, marxismo, semiologia, etc.

16. VERÓN, Eliseo - Introducción: hacia una ciencia de la comunicación social. In: VERÓN, Eliseo et alii. Lenguage y comunicación social. Buenos Aires, Nueva Visión, 1969 , p. 17.
17. ZEMS, Abraham - Les optiques cohérentes. Revue d'Esthétique, 20(1): 40-1, 1967.

18. Cf. para um melhor conhecimento desta problemá ica: DUFRENNE, Mikel.

Esthétique et philosophie. op.cit. Oferece uma razoável visão de conjunto destas objeções, principalmente no artigo ' $L$ 'art estil langage?',. p. 73-112.

LANGER, Suzanne - The philosophy in a new key. Cambridge, University Press, 1941.

DELla VOLPE, Galvano - Crítica del gusto. Milano, Feltrinelli, 1960.

LYOTARD, Jean-François - Discours, figure. Paris, Klinsckseick, 1971.

GOODMAN, Nelson - Language of art an approach to a theory of symbols. New York, The Bobbs-Merril Co.. 1968. 